\title{
A Taxonomy for Supply Chain Management Literature
}

\author{
Ismail Capar* \\ Fusun Ulengin** \\ Arnold Reisman ${ }^{\wedge}$ \\ **Istanbul Technical University, Istanbul, Turkey \\ ^ Graduate School of Management, Sabanci University, Istanbul, Turkey \\ Reisman and Associates, Shaker Heights, OH. USA \\ ^ Corresponding author, reismana@cs.com
}

16 October 2003

\begin{abstract}
This paper presents a scheme for classifying the Supply Chain Management (SCM) literature. SCM is broadly defined to include all classical business functions and theoretic management disciplines which impacted this emerging field. Consequently, its literature is very disjoint and disparate. It transcends several academic disciplines and professions. This paper presents a way to define the field in its entirety and delineate all of its facets in a manner that is parsimonious yet discriminating. Sample articles are classified to illustrate the descriptive power and the parsimony of this taxonomy.
\end{abstract}

Key words: Supply Chain Management, Taxonomy, Classification 


\section{A Taxonomy for Supply Chain Management Literature}

\section{Introduction}

\subsection{Background}

Supply chain management (SCM) in general, is a synthesis of what was previously considered to be management of a number of separable business functions on the one hand, and several relatively independent theoretic domains on the other. Among others these include; purchasing, inbound logistics, inventory control, contracting, manufacturing/outsourcing, performance/efficiency theory, relationship management, information systems, systems theory, mathematical and computer modelling, optimization etc. SCM content articles appear in rather disparate journals ranging from Management Science to Industrial Marketing Management. Consequently, its literature is very disjoint. Hence this paper is an attempt at a synthesis to show how the threads or strains and weaving patterns of the various contributions fit together as part of the total tapestry.

\section{SCM Literature}

\subsection{Epistemology of SCM}

The literature of SCM has exploded during the last decade. It has become a major subtopic of production and operations management. Although today, SCM encompasses all activities involved in producing and delivering a final product or service, from the various sub-tiers to end-customers, it developed from multi-echelon inventory models (Clark and Scarf, 1960). Several trends in logistics management have emerged subsequently. Each of these broadened while improving the focus of the previous. The notion of cost-cost tradeoffs was introduced showing that the lowest total cost might not be achieved by pursuing the lowest cost of each logistics process constituent. Hence, the concept of logistics integration was introduced by Bowersox (1969).

In their practices, many companies recognized the fact that in optimizing logistics costs it was compulsory to include all relevant sub-tiers inside and outside of the firm, in terms of physical and information flows. These include all suppliers, and the entire distribution network. The challenge for logistics managers became to integrate logistical performance across all operating facets of a business. Meanwhile, researchers such as Houlihan (1985, 1988), Lee and Billington (1993), Cooper and 
Ellram (1993), and Thomas and Griffin (1996) started to introduce and implement the SCM concept.

Contributing to the SCM literature today, are knowledge domains such as operation research, operations management, management science, system dynamics, economics, marketing, and information technology.

Among others, the following OR/MS and Operations Management subfields impact SCM:

(i) multi echelon inventory models \{Clark and Scarf (1960, 1962), Chen (1998), Chen and Zheng (1994, 1997), Erkip et al.(1990), Bessler and Veinott(1966), Graves (1985), Lee and Moinzadeh (1987a,b) \};

(ii) location models \{Cohen and Lee (1988), Geoffrion and Graves (1974), Revelle and Laporte (1996)\};

(iii) performance measurement \{Harper (1984), Rolstadås (1995), Miller (2001), Bowersox and Closs (1996), Beamon (1998,1999), Basu 2001\};

(iv) Inventory and distribution \{Federgruen and Zipkin(1984), Blumenfeld et al. (1985), Burns et al. (1985), Chan and Simchi-Levi (1998)\}

There are also some exemplary contributions to the SCM literature from outside the traditional OR/MS industrial engineering fields. Among these are:

(i) Forrester (1961) contributed to the SCM literature from the economics and system dynamics point of view. He analysed the growth, decline, and growing variation in a supply chain which is known as "bullwhip effect" (Lee et al. 1997).

(ii) Cachon and Zipkin (1999) applied the Nash equilibrium for competitive inventory policies in a two-stage supply chain.

(iii) Postponement (Alderson, 1950), Today postponement is widely used in inventory control and production system (Jones and Riley (1984), Zinn and Levy (1988), Zinn and Bowersox (1988), Lee and Billington (1995), Aviv and Federgruen (2001))

(iv) Price incentives (Blattberg et al, 1981).

(v) Relationship management (Pyke and Johnson,2002),

(vi) Social responsibility Carter and Jennings (2002), 


\subsection{SCM literature growth}

The accumulation of SCM articles listed on the PROQUEST and ELSEVIER databases as of end June 2003 is shown in Figure 1. During the last five complete years of record the literature accumulated 4.5 times the number of articles published up to and including 1997. In the first half of 2003, the number of published articles has exceeded $70 \%$ of those published in 2002 . The year 2003 may well be the takeoff year for the above being an exponential growth curve.

\section{Cumulative Articles}

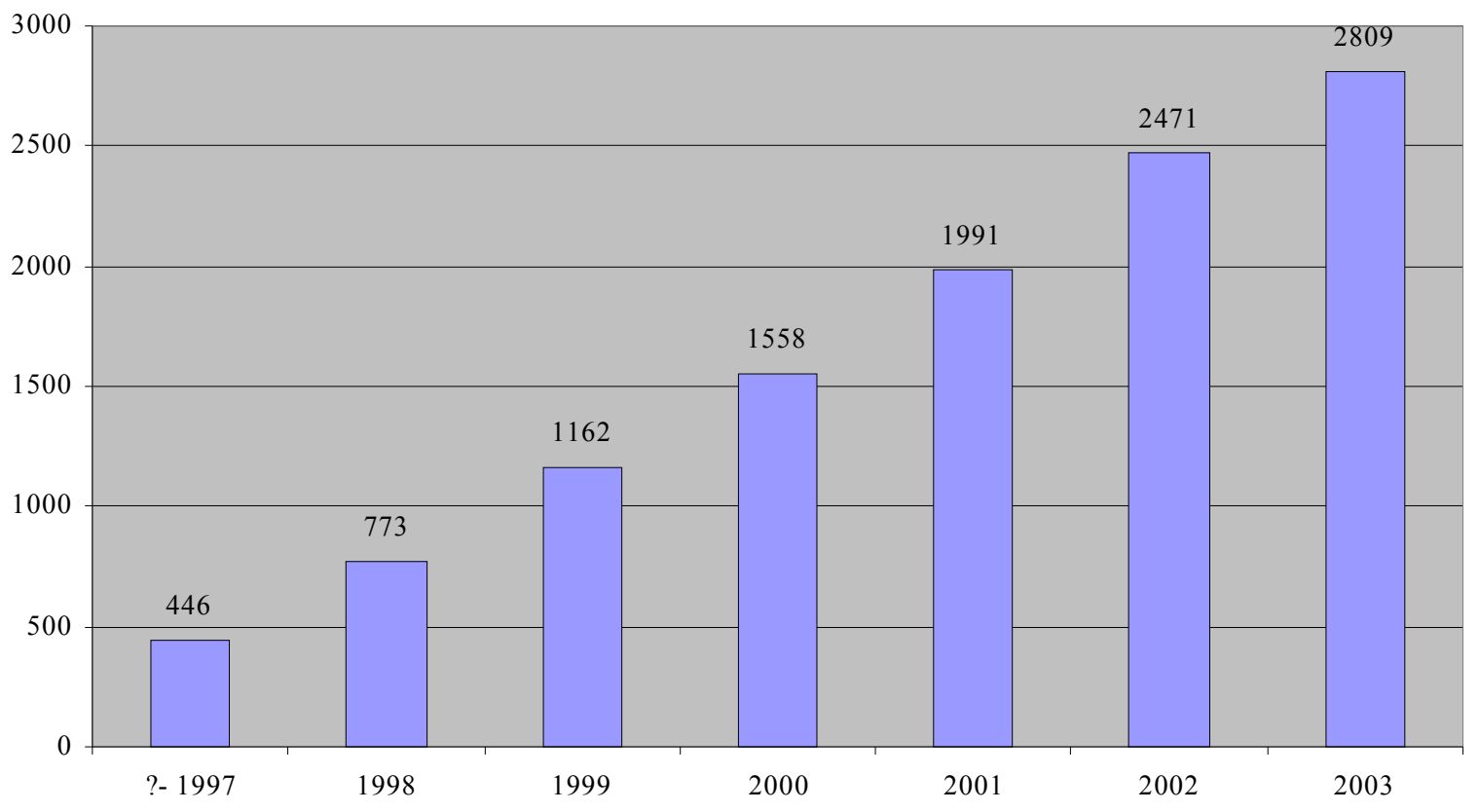

Figure 1: Number of SCM articles published in refereed journals

\subsection{Paper organization}

Section 3 of this paper discusses the need for a taxonomy at this stage of SCM literature development and taxonomies in general. Section 4 provides a taxonomy that can be used to classify any and all contributions to the literature of SCM. Several well known papers were used to calibrate both the taxonomy and the respective classifiers' - authors of this paper - judgments. Section 5 illustrates this classification, and Section 6 of concludes the paper.

\section{Need for a SCM Taxonomy: a Discussion}


As important as it is to publish the results or findings of good research in a given field of knowledge it is also important to systematically review the totality of such publications on some periodic basis (Goffman (1980), Abbott (1988), Gupta (1996)). Systematic reviews of the literature represent research on research or what is sometimes called meta research (MR). The objectives of this MR is to unify the domain of SCM knowledge and or to expand or generalize it while at the same time consolidating this field of knowledge and practice. There are at least two efficient and effective ways of consolidating knowledge in a given field. One of these is to create a taxonomy and the other is to create a generalized framework (a general model or theory) that subsubsumes all existing models facts or theories within the field. The above two modes are not mutually exclusive. In fact they are complimentary. At times, as was the case with the Periodic Table of Chemical Elements (Mendeleev (1889)), an underlying theory is imbedded within a taxonomy and such is the case with SCM.

A taxonomy for a given field of knowledge displays the field's domain in terms that are easy to understand, to communicate, to teach, to learn, and to work with. The taxonomy can be used:

1. To efficiently and effectively classify any and all contributions/ for purposes of storage, recall, sorting, and or statistical analyses and because such classification results are meaningfully machine readable they in turn clearly enable further meta research publications (Reisman (1992)).

2. To identify voids in the literature and hence directions/specifications for research in need of being performed publications (Reisman (1988),(1989))

3. Classification of papers based on a taxonomy makes similarities and differences among the respective studies very clear. Significantly, it does so in a most efficient and effective a manner.

The evolution of SCM from the early articles of Clark and Scarf (1960) up to and including June 2003 shows at least 2909 articles. ${ }^{1}$ Consequently, the time is now ripe for a general mapping of this literature in a manner that will vividly provide a panoramic view of what exists and will clearly identify any existing gaps in the state of the art as suggested by Reisman ((1989), (1994) and (1992)). Hence there is a need for an SCM taxonomy which:

\footnotetext{
${ }^{1}$ This number represents only that part of the SCM literature appears on the PROQUEST and ELSEVIER databases
} 
Graphically, symbolically or both, will vividly display the similarities and the differences among the various contributions, thus demonstrating the relationship of all contributions and the practical applications of each to other. It will provide a framework by which all of the existing knowledge can be systematically filed and therefore recalled efficiently and effectively. By providing what amounts to an aerial view- a picture of the territory- it will identify the voids in the literature... Knowledge consolidation is a means to various ends, and it is also an end itself. It is a means toward the end of more efficient and more effective teaching and learning of new or existing knowledge. It is a means toward the end of more efficient storage and more effective recall and/or retention of knowledge. It is a means toward a more efficient and more effective processes of research leading to the yet unknown, to the design of the yet unavailable, and it is a means toward more efficient problem solving... (Reisman 1979)

\section{Morever,}

The key to taxonomy effectiveness rests on criteria of comprehensiveness, parsimony and usefulness. Obviously, to be effective, a taxonomy must represent the full spectrum of the research chosen for categorization. Thus, comprehensiveness is a necessary condition for effectiveness. It is, however, not sufficient. To further be effective, a taxonomy should be parsimonious. It should not include unnecessary categories. Finally, to be considered effective, the taxonomy should be robust and generally useful. The categories should be reasonably if not mutually exclusive, i.e., non-overlapping, reasonably distinct, meaningful, commonplace, and descriptive to allow utilization by a wide variety of interested persons. (Vogel And Weterbe (1984)

A taxonomy is not only a tool for systematic storage efficient and effective teaching/learning and recall for usage of knowledge but it is also a neat way of pointing to knowledge expansion and building. It identifies voids, potential theoretical increments or developments and potential applications for the existing theory. SCM has already generated a large enough literature allowing it to be considered as a separate and distinct field of knowledge. The increasing interest in $\mathrm{SCM}$ as an alternative tool for performance measurement makes a systematic elaboration of this field more crucial in helping researchers on-board as well as in attracting potential newcomers to the field.

Clearly, as is the case in one of the greatest and best-known taxonomies of all time, the Periodic Table of Elements (PTE), Mendeleev (1889), what is presented here is open for incremental evolutions. A taxonomy is very much dependent on the definition of the boundaries of the universe it classifies. Hence, the classification developed in this study is open to expansion as the scope of SCM enlarges. With the PTE as a role model, one can discuss the usage of a taxonomy to knowledge building. The PTE has always indicated cells which described with great efficiency elements yet to be discovered. Thus if and when the SCM taxonomy is used to classify the entire set of extant articles, the cells remaining empty will vividly show the voids in the literature. To be sure some of those void "cells" have a greater 
research interest than others; however, they (the empty cells) will all create a full set of specifications for the researcher to pursue. This is amply demonstrated in Reisman (1992). If on the other hand only a sample of the extant papers are classified then the probability that a void identified is truly so increases with the sample's richness and representativeness.

Clearly, as is the case in one of the greatest, and best-known taxonomies of all time, Periodic Table of Elements, what is presented here is open for incremental evolutions. A taxonomy is very much dependent on the definition of the boundaries of the universe it classifies. Hence, the classification developed in this study is open to expansion if and when the scope of SCM enlarges.

The current attempt to define a taxonomy for SCM may have its own disadvantages but it does not suffer from ambiguity. In fact it may be too detailed in terms of branching levels. Though this makes its application cumbersome, it does increase its descriptive powers. Moreover, it is easy to aggregate sub-classifications and/or pruning outer branches. The inverse, e.g., having to deaggregate classifications once made, typically requires much effort. The authors are open to suggestions. The taxonomy proceeds in an arborescent way Reisman (1992), as illustrated in Figure 2.

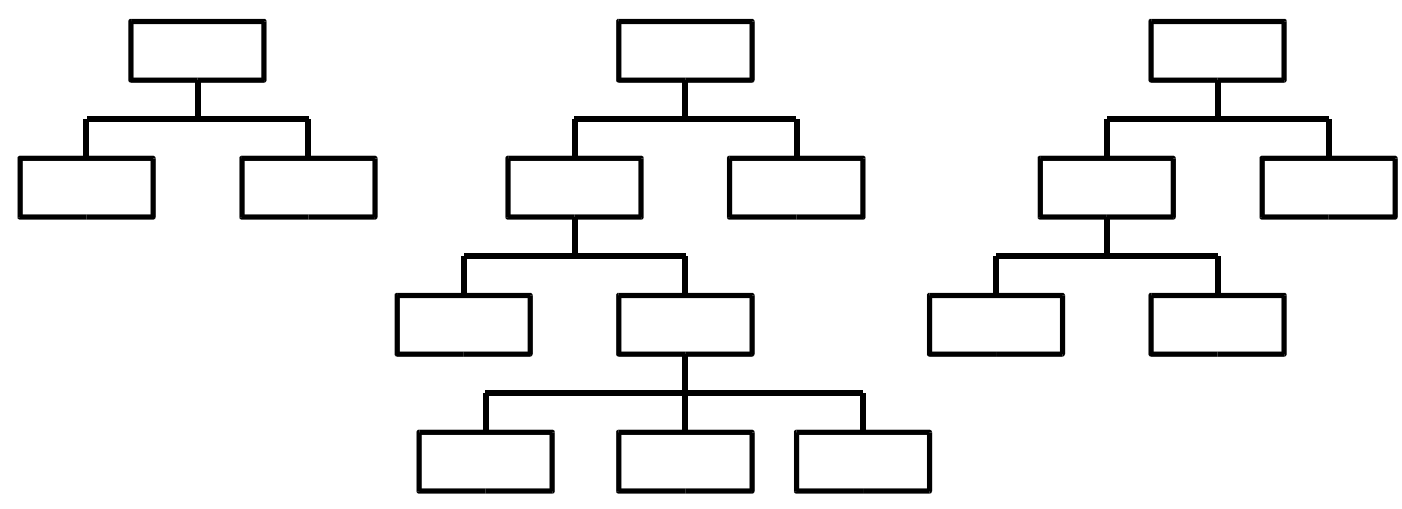

Figure 2: Attribute Vector Description Based Taxonomy

\section{A Taxonomy for SCM}


As indicated, the SCM related literature is first classified on four basic factors; the type of study reported on, the structure of the SC involved, the SC activities addressed, and the degree of decision making and of information sharing. Under each of these factors, the most discriminating attributes are listed. The full taxonomy is illustrated in Figure 2. In the proposed taxonomy, each contribution can be given an identification code based on seventeen domains grouped in four classes or keys for classification:

Key 1: Type of Study. This is subdivided into six domains. The first domain describes the modelling used if any, the second describes the information technology involved, the third addresses the supplier- buyer relationships, the fourth specifies the performance measures considered, the fifth shows that the paper represented a case study or a survey. Lastly, the sixth indicates whether the paper provided a taxonomy, classification or was basically review of the literature.

Key 2: Structure of Supply Chain. This is subdivided into three domains characterising the supply chain involved. The first involves a two-stage supply chain, the second a serial supply chain where each stage has one member, and the third has more than two stages and at least one stage has more than one member.

Key 3: Product Properties This is subdivided into nine domains characterising the product(s) involved. These involve product; classification, demand patterns, number(s) and relationships, life cycle, ownership, production strategy, status, priority of delivery, packaging and handling.

Key 4: Supply Chain Activities. This is subdivided into five domains identifying the different SC activities e.g., sourcing and procurement, production, inventory management, transportation, and return or aftersales.

Key 5: Decision Making and Degree of Information Sharing. This is subdivided into three domains identifying the SC decision makers, the types of decisions involved, and the level information sharing if any.

Key 6: Solving Procedure. This is subdivided into three domains identifying the ways used to solve the SC models formulated.

\section{Type of Study}

1. Modelling

1.1. Mathematical Model

1.2. Simulation Model 


\subsection{Mixed Model}

2. Technology Usage in SC

2.1. Areas of IT Usage

2.1.1. Demand Realization

2.1.2. Distribution and retailing management

2.1.3. Manufacturing Management

2.1.4. Orders Processing

2.1.5. Information sharing throughout supply chain

2.2. Types of Technologies

2.2.1. Internet

2.2.2. EDI

2.2.3. Other ITs used for increasing SC competitiveness

3. Relationship Management

3.1. Supplier- Buyer Relationship

3.1.1. Strategic alliances / partnership / collaboration

3.1.2. Contract management

3.1.3. Conflict resolution

3.1.4. Negotiation

3.2. Supplier Development

3.3. Buyer - Supplier Coordination

3.4. Customer Relationship

3.5. Relationship with Environment

4. Performance Measurement

4.1. Balanced Scorecard Based Approaches

4.2. SCOR Based Approaches

4.3. Other Performance Measures

4.3.1. Operational performance measures

4.3.2. Financial measures

4.3.3. Assets related measures

4.3.4. Customer satisfaction related measures

4.3.5. Two or more types of other performance measures considered at the same time

5. Case Studies, Surveys, and Benchmarks

6. Taxonomy, Classification, and Literature Review

\section{Structure of Supply Chain}

1. Two stages SC

1.1. One Vendor, One buyer

1.2. One Vendor, Multiple Buyers

1.3. Multiple Vendors, Multiple Buyers

1.4. Multiple Vendors, One Buyer

2. Serial SC (n stages (more than two), one member at each stage)

3. Network SC (multi stages (more than two), at least one of the stage has more than one members)

\section{Product Properties}

1. Product Classification

1.1. Durability and Tangibility

1.1.1. Durable Goods

1.1.2. Perishable/Dated Goods

1.2. Consumer Goods

1.2.1. Convenience goods

1.2.2. Shopping goods

1.2.3. Speciality goods

1.3. Industrial Goods

1.3.1. Raw Materials

1.3.1.1. Farm Products 
1.3.1.2. Natural Products

1.3.2. Manufactured Materials

1.3.2.1. Component materials

1.3.2.2. Component parts

1.3.3. Supplies

1.3.4. Accesories

2. Demand Distribution

2.1. Normal Distribution

2.2. Poisson Distribution

2.3. Distribution function or mean and variance of demand known

2.4. Other type of known distribution used

3. Demand Pattern

3.1. Functional Products

3.2. Innovative Products

4. Product Numbers and Relationships

4.1. Single Product

4.2. Multi Product Independent Demand

4.3. Multi Product Dependent Demand

5. Product Life Cycle

5.1. Introductory Stage

5.2. Growth Stage

5.3. Maturity Stage

5.4. Decline Stage

6. Product-Inventory Ownership

6.1. Buyer and supplier are the owner of the product that on their warehouses.

6.2. Supplier is the owner of products until products are either sold or used by buyer.

6.3. Buyer is the owner of the products after order is confirmed.

6.4. Inventory cost is shared by the buyer and the supplier

7. Production Strategy

7.1. Make to Stock

7.2. Make to Order

7.3. Engineer to Order

8. Product Status

8.1. Finished Goods

8.2. WIP And Subassemblies

8.3. Raw Materials

8.4. MRO Products

8.5. Spare Parts

8.6. Pipeline Inventory

9. Delivery Priority

9.1. High Priority Goods

9.2. Regular Priority Goods

9.3. Not Prioritized

10. Packaging and Handling

10.1. Bulk

10.2. Container

10.3. Boxed

10.4. Special Handling Required

10.4.1. Hazardous Material

10.4.2. Refrigerated Goods

Supply Chain Activities

1. Sourcing / Procurement

1.1. Make or Buy Decision

1.2. Supply Source Selection

1.3. Purchase Timing and Quantities

1.4. Supplier Evaluation

2. Production

2.1. Type, Number, Size, Location, and Layout of Production Points

2.2. Production and Capacity Planning 
2.3. Product Design for Manufacture and Distribution

2.4. Process Design

2.5. Product Mix Selection

2.6. Sequencing and Scheduling

3. Inventory Management

3.1. How much inventory to produce/order

3.2. Inventory control policies

3.2.1. Continuous Models

3.2.1.1. Base Stock Policy

3.2.1.2. (Q,R) Policy

3.2.1.3. Other continuous review policies

3.2.2. Peridodic Review Models

3.3. Storage Policies

3.3.1. Stock-keeping unit (SKU) storage

3.3.2. Job-lot storage

3.3.3. Crossdocking

3.4. Type, number, size, and location of stocking points

3.5. Product mix at stocking points

3.6. Forecasting

3.6.1. Qualitative forecasting methods

3.6.2. Time Series forecasting methods

3.6.2.1. Static forecasting methods

3.6.2.2. Adaptive forecasting methods

3.6.3. Causal Forecasting Methods

3.6.4. Simulation forecasting methods

4. Transportation and Delivery

4.1. Geographic Characteristics

4.1.1. Intercity transportation

4.1.2. Intercountry transportation

4.2. Transportation Modality

4.2.1. Air

4.2.2. Sea

4.2.3. Truck

4.2.4. Rail

4.2.5. Pipeline

4.2.6. Package carriers (e.g. Fedex, UPS)

4.2.7. Intermodal transport

4.3. Freight Consolidation and Load Building

4.3.1. Mode

4.3.2. Lane

4.3.3. Location

4.4. Carrier Type, Carrier, and Carrier Service Selection

4.5. Vehicle-Carrier routing

4.5.1. Demand Realization

4.5.1.1. Stochastic

4.5.1.2. Deterministic

4.5.2. Number of Points of Origin

4.5.2.1. Single Origin

4.5.2.2. Multiple Origin

4.5.3. Number of Vehicle

4.5.3.1. Single Vehicle

4.5.3.2. Multi Vehicle

4.5.4. Vehicle Homogeneity (Capacity)

4.5.4.1. Similar vehicles

4.5.4.2. Different vehicles

4.5.5. Capacity Consideration

4.5.5.1. Capacitated vehicles

4.5.5.2. Uncapacitated vehicles

4.5.6. Load Splitting Constraint

4.5.6.1. Splitting of load 
4.5.6.2. Unsplitting of Load

4.5.7. Precedence/coupling Constraint

4.5.7.1. Precedence Constraints

4.5.7.2. Coupling Constraints

4.5.8. Trip Type

4.5.8.1. Round trip

4.5.8.2. One way

4.5.9. Transportation Cost

4.5.9.1. Neglected

4.5.9.2. Linear cost

4.5.9.3. Nonlinear cost

4.5.9.4. Fixed cost plus linear transportation cost

4.5.9.5. Fixed cost plus nonlinear transportation cost

4.5.10. Transportation time

4.5.10.1. Neglected

4.5.10.2. Changes with respect to distance

4.5.11. Distance/Cost Properties

4.5.11.1. Assymetric

4.5.11.2. Simetric

4.5.12. Other Proporties

4.5.12.1. Time Window

4.5.12.2. Backhouls

4.6. Picking and Packing

5. Return / After Sales

5.1. Claim processing

5.2. Spare parts inventory management

5.3. Recall Campaign

5.4. Reverse Logistics

5.4.1. Defective product shipment

5.4.2. Return shipment

5.4.2.1. Excess inventory

5.4.2.2. Serviceable/repairable products

5.4.2.3. Obsolete products

5.4.2.4. Reusable parts

5.5. Scheduling and managing the individual return

6. Revenue and Coordination Management

6.1. Pricing

6.1.1. Centralized Pricing

6.1.2. Decentralized Pricing

6.2. Quantity discounts

6.3. Rebates and price discounts

6.4. Incentives

\section{Decision Making and Degree of Information Sharing}

1. Decision Maker

1.1. Each member makes its own decision (in case of serial or complex sc)

1.2. Buyer

1.3. Vendor

1.4. Collaborative decision making $(\mathrm{CDM})$

1.5. Buyer - Vendor

1.6. Buyer - CDM

1.7. Vendor - CDM

1.8. Buyer - Vendor $-\mathrm{CDM}$

2. Decision type

2.1. Coordinated

2.2. Uncoordinated

2.3. Coordinated - Uncoordinated 
3. Information sharing

3.1. Information not shared

3.2. Partial information sharing

3.3. Full information sharing

3.4. Information not shared - Partial information sharing

3.5. Information not shared - Full information sharing

3.6. Partial information sharing - Full information sharing

3.7. Full - Partial - No information sharing

\section{Solving Procedure}

1. Convexity of the mathematical model

1.1. Convex Linear model

1.1.1. Linear programming model.

1.1.2. Discrete or Mixed linear programming model.

1.1.3. Dynamic Programming Model

1.1.4. Fuzzy linear programming model.

1.1.5. Chance constrained or stochastic linear programming model.

1.1.6. Graphical presentation

1.2. Convex non-linear model.

1.2.1. Polynomial hard problem.

1.2.2. Non-polynomial hard problem

1.2.3. Ratio Form.

1.3. Non-convex linear model.

1.4. Graphical presentation

1.5. Non-convex non-linear model.

2. Solving Procedure

2.1. No solving method proposed or standard method is used.

2.2. Single stage solving method.

2.2.1. Exact method explicitly presented.

2.2.2. Approximated method.

2.2.3. Heuristic method.

2.2.4. Meta-heuristic method.

2.2.5. Graphical

2.3. Multi-stage.

2.3.1. Exact method explicitly presented.

2.3.2. Approximated method.

2.3.3. Heuristic method.

2.3.4. Meta-heuristic method.

3. Efficiency measures provided by the solution.

3.1. Single-valued measures.

3.2. Multi-valued measures.

3.2.1. Exact multi-valued measures

3.2.2. Fuzzy multi-valued measures

3.3. Stochastic measures

3.3.1. Stochastic single-valued measures

3.3.2. Stochastic multi-valued measures

Figure 3: A Taxonomy of Supply Chain Management Literature

\section{Illustrative classifications:}

At the outset, the authors of this paper were interested in seeing whether or not the taxonomy of Figure 3 was robust enough and yet discriminating and parsimonious to take on several papers known to these authors as representing rather different approaches to SCM. The SCM -related articles are first classified on six 
basic factors. Under each of these factors, the most discriminating attributes are then listed. Hence, each contribution can be given an identification code based on classes or keys for classification:

Exhibit 1.

\title{
The Value of Information Sharing in a Two-Level Supply Chain
}

\author{
Hau L. Lee, Kut C. So, Christopher S. Tang
}

Many companies have embarked on initiatives that enable more demand information sharing between retailers and their upstream suppliers. While the literature on such initiatives in the business press is proliferating, it is not clear how one can quantify the benefits of these initiatives and how one can identify the drivers of the magnitudes of these benefits. Using analytical models, this paper aims at addressing these questions for a simple two-level supply chain with nonstationary end demands. Our analysis suggests that the value of demand information sharing can be quite high, especially when demands are significantly correlated over time.

Management Science 2000

Vol 46 No:5

Using mathematical modelling this article investigates the value of (demand) information sharing in a bi-level SC using EDI technology. Demand faced by a retailer is correlated over a time horizon and each member uses the periodic inventory review policy. The authors compare the effect of information sharing on buyer-vendor decisions. The model used for the problem is a stochastic model with an approximate solution and the results are compared based on inventory and cost reductions. Hence, the paper is classified as:

$(1.1 / 2.1 .5 / 2.2 .2)(1.1)(2.5)(3.2 .2)(1.2 . / 1.3 / 3.4)(1.1 .5 / 2.2 .2 / 3.1)$

Exhibit 2.

\section{NEAR-OPTIMAL ECHELON-STOCK $(R, n Q)$ POLICIES IN MULTISTAGE SERIAL SYSTEMS \\ Fangruo Chen, Yu-Sheng Zheng}

We study echelon-stock $(R, n Q)$ policies in a multistage, serial inventory system with compound Poisson demand. We provide a simple method for determining near-optimal control parameters. This is achieved in two steps. First, we establish lower and upper bounds on the cost function by over- and under-charging a penalty cost to each upstream stage for holding inadequate stock. Second, we minimize the bounds, which are simple, separable functions of the control parameters, to obtain heuristic solutions. We also provide an algorithm that guarantees an optimal solution at the expense of additional computational effort. A numerical study suggests that the heuristic solutions are easy to compute (even for systems with many stages) and are close to optimal. It also suggests that a traditional approach for determining the order quantities can be seriously suboptimal. All the results can be easily extended to the discrete-time case with independent, identically distributed demands. 
A serial supply chain is mathematically modelled to determine $(Q, R)$ values for a continuous inventory review system with Poisson end-item demand. The authors offer a coordinated decision making strategy for overall supply chain in a full demand information sharing environment. They present a stochastic model solved by a multi stage algorithm, which uses approximation and heuristics. In addition, they present an exact solution methodology. Thus its classification based on Figure 3 is:

$(1.1)(2)(2.2)(3.1 / 3.2 .1 .2)(2.1 / 3$ 3) $(1.1 .5 / 2.2 .1 / 2.2 .3 / 3.3 .2)$

\section{Exhibit 3.}

\section{Optimizing Strategic Safety Stock Placement in Supply Chains Stephen C. Graves, Sean P. Willems}

Manufacturing managers face increasing pressure to reduce inventories across the supply chain. However, in complex supply chains, it is not always obvious where to hold safety stock to minimize inventory costs and provide a high level of service to the .nal customer. In this paper we develop a framework for modeling strategic safety stock in a supply chain that is subject to demand or forecast uncertainty. Key assumptions are that we can model the supply chain as a network, that each stage in the supply chain operates with a periodic-review base-stock policy, that demand is bounded, and that there is a guaranteed service time between every stage and its customers. We develop an optimization algorithm for the placement of strategic safety stock for supply chains that can be modeled as spanning trees. Our assumptions allow us to capture the stochastic nature of the problem and formulate it as a deterministic optimization. As a partial validation of the model, we describe its successful application by product flow teams at Eastman Kodak. We discuss how these flow teams have used the model to reduce finished goods inventory, target cycle time reduction efforts, and determine component inventories. We conclude with a list of needs to enhance the utility of the model.

Manufacturing \& Service Operations Management

Vol. 2, No. 1

This article presents a mathematical formula for determining how much inventory should be kept in each stage and member of a complex supply chain with an application at Eastman Kodak. WIP, subassemblies, and pipeline inventories are managed with a periodic inventory review policy. All information is presumed known by the central decision maker who makes a coordinated decision. It is a dynamic programming model solved with existing methods. The efficiency measure is a single-valued exact solution. Hence:

$(1.1 / 5)(3)(1.3 .2 / 8.2 / 8.6)(3.1 / 3.2 .2)(2.1 / 3.3)(1.1 .3 / 2.2 .1)$ 
Exhibit 4.

\section{What is the Right Supply Chain for Your Product \\ Marshall Fisher}

Never has so much technology and brainpower been applied to improving supply chain performance. Point-of-sale scanners allow companies to capture the customer's voice. Electronic data interchanges lets all stages of the chain hear that voice and react to it by using flexible manufacturing, automated warehousing, and rapid logistics. And new concepts such as quick response, efficient consumer response, accurate response, mass customization, lean manufacturing, and agile manufacturing offer models for applying the new technology to improve performance.

Harvard Business Review March - April 1997

This paper classifies SC strategies and relationships among operational performance, customer satisfaction related performance measures, and product properties which can be applied to all SC structures. Moreover, the author shares the experience of different cases and classifies the products as either functional or innovative. Other topics discussed in the article are product design for manufacture and distribution, base stock continuous inventory control application, qualitative forecasting, and pricing.

$$
\text { (4.3.1/4.3.4/5/6) (3) (2.1/2.2) (2.3/3.2.1/3.6/6.1) } 00
$$

\section{Exhibit 5.}

\section{Quantifying the Bullwhip Effect in a Simple Supply Chain: The Impact of Forecasting, Lead Times, and Information \\ Frank Chen, Zvi Drezner, Jennifer K. Ryan, David Simchi-Levi}

An important observation in supply chain management, known as the bullwhip effect, suggests that demand variability increases as one moves up a supply chain. In this paper we quantify this effect for simple, two-stage supply chains consisting of a single retailer and a single manufacturer. Our model includes two of the factors commonly assumed to cause the bullwhip effect: demand forecasting and order lead times. We extend these results to multiple-stage supply chains with and without centralized customer demand information and demonstrate that the bullwhip effect can be reduced, but not completely eliminated, by centralizing demand information.

Management Science 2000

Vol 46, No.3

This paper presents a mathematical and a simulation model for one vendor, one buyer and a serial supply chain. They determine how much inventory should be kept based on a time series forecasting method. Two cases (information not shared and information fully shared), are compared resulting in a ratio-form model. The model is solved by approximation and a lower bound is derived for the exact solution with a single-valued measure. 
$(1.1 / 1.2)(1.1 / 2)()(3.1 / 3.2 .2 / 3.6 .2)(3.5)(1.2 .1 .3 / 2.2 .2 / 3.1)$

\section{Exhibit 6.}

\section{Coordinating Production and Delivery Under a $(z, Z)$-Type Vendor- Managed Inventory Contract Michael J. Fry, Roman Kapuscinski, Tava Lennon Olsen}

This paper models a type of vendor-managed inventory (VMI) agreement that occurs in practice called a $(z, Z)$ contract. We investigate the savings due to better coordination of production and delivery facilitated by such an agreement. The optimal behavior of both the supplier and the retailer are characterized. The optimal replenishment and production policies for a supplier are found to be up-to policies, which are shown to be easily computed by decoupling the periods when the supplier outsources from those when the supplier does not outsource. A simple application of the newsvendor relation is used to define the retailer's optimal policy. Numerical analysis is conducted to compare the performance of a single supplier and a single retailer operating under a $(z, Z)$ VMI contract with the performance of those operating under traditional retailer-managed inventory (RMI) with information sharing. Our results verify some observations made in industry about VMI and show that the $(z, Z)$ type of VMI agreement performs significantly better than RMI in many settings, but can perform worse in others.

Manufacturing \& Service Operations Management Vol. 3, No. 2

A mathematical model is used to evaluate the effect of contract on coordination of production and delivery in a two stage - one buyer one vendor- supply chain. The authors assumed demand distribution to be known and seek to find purchase timing and quantities and how much inventory should be kept under a periodic inventory review policy. The article evaluates the optimal replenishment and production policies when buyer and vendor fully share information but decisions are made in an uncoordinated fashion. They propose a stochastic model for this problem and solve it with previously known solution methods. Results are compared according to single valued measures. Hence,

(1.1/3.1.2) (1.1) (2.3) (1.3/3.1/3.2.2) (1.5/2.2/3.3) (1.1.5/2.1/3.1)

\subsection{Summary and discussion of the illustrative classifications:}

The above classifications for the illustrative examples are reproduced in Table 1 . Viewed this way it can be seen that all but one (Exhibit 4) involve a mathematical model. Namely, all others have (1.1.....) as the first entry in key 1 . The fourth paper does not but concentrates on discussing performance and customer satisfaction measures. Hence the first entry is (4.3.1....), and because there is no mathematical model involved there is no discussion of solving procedures. This is recognized by noting the last field to be empty e.g. (). Because this paper also differs from the rest in not addressing decision making, and information sharing, the next to the last field is also empty e.g., (). Similarly, Exhibit 1 and Exhibit 6 provide single-valued measures as part of their solutions while Exhibit 2, offers a stochastic multi-valued 
measure. Thus Table 1 vividly shows the similarities and the differences among the papers included in this sample. Much like the periodic table of chemical elements, it does so in both an effective and efficient manner. If and when all of the extant SCM articles are so classified the result will easily identify the voids in the literature e.g., meaningful combinations of Figure 3 attributes not present in that extended Table 1. A development such as that will be of great help to $\mathrm{PhD}$ candidates in search of a topic and to their dissertation committee members in considering proposals.

In the meantime Figure 3 can be used to define SCM as a field of knowledge and practice in introducing the subject to neophytes. Seasoned SCM researchers, authors and instructors may find it a useful tool for systematically filing and efficiently recalling papers seen. Firms dependent on cost-effectiveness of their SC may use it for purposes of SC configuration redesign/reengineering and logistics firms may use it for proposal generation.

\section{Table 1. Summary of the illustrative classifications}

\section{$\underline{\text { Exhibit } \quad \text { Classification }}$}

1. $(1.1 / 2.1 .5 / 2.2 .2)(1.1)(2.5)(3.2 .2)(1.2 . / 1.3 / 3.4)(1.1 .5 / 2.2 .2 / 3.1)$

2. $(1.1)(2)(2.2)(3.1 / 3.2 .1 .2)(2.1 / 33)(1.1 .5 / 2.2 .1 / 2.2 .3 / 3.3 .2)$

3. $(1.1 / 5)(3)(1.3 .2 / 8.2 / 8.6)(3.1 / 3.2 .2)(2.1 / 3.3)(1.1 .3 / 2.2 .1)$

4. $(4.3 .1 / 4.3 .4 / 5 / 6)(3)(2.1 / 2.2)(2.3 / 3.2 .1 / 3.6 / 6.1) 00$

5. $(1.1 / 1.2)(1.1 / 2) 0(3.1 / 3.2 .2 / 3.6 .2)(3.5)(1.2 .1 .3 / 2.2 .2 / 3.1)$

6. $(1.1 / 3.1 .2)(1.1)(2.3)(1.3 / 3.1 / 3.2 .2)(1.5 / 2.2 / 3.3)(1.1 .5 / 2.1 / 3.1)$

\section{Concluding Remarks}

There is always a subjective side to selecting illustrative papers. The above represent different periods, different journals, differing paths to theory extension, differing application sectors and differing research strategies. Even the respective authors emanate from different countries, indeed different continents.

As in any new sub-discipline of Management Science, the SCM literature is growing exponentially. This literature is recording advancements in theory and in solution methodology while at the same time expanding its domain of applications.

Because a major objective for this taxonomy is to systematically identify the voids in the literature ${ }^{2}$ of SCM, we erred on the side that might appear to have an excess of detail. It may be that the Figure 3 taxonomy is too detailed than is necessary for common usage, thus violating parsimony. However, experience shows that it is easier to aggregate data in hand than not to have collected it in sufficient detail in the first place, Reisman (1979). Lastly, no taxonomy should be considered fixed for all time. It should evolve as the field it addresses evolves over time. Even

\footnotetext{
${ }^{2}$ As demonstrated for other OR/MS disciplines in Reisman [(1998), (1999), and (1992)]
} 
the Periodic Table of chemical elements has been, and remains in the state of evolution.

\section{References:}

Abbott A. (1988) The system of professions: an essay on the expert division of labor. University of Chicago Press, Chicago, IL,.

Alderson, W. (1950) Marketing efficiency and the principle of postponement. Cost and Profit Outlook 3 (Sep),

Aviv Y. and A. Federgruen (2001) Capacitated Multi-Item Inventory Systems with Random and Seasonally Fluctuating Demands: Implications for Postponement Strategies. Vol. 47, No. 4. pp. 0512-0531

Basu R, (2001) New Criteria of Performance Management: A Transition From Enterprise to Collaborative Supply Chain," Measuring Business Excellence Vol. 5 No. 4, pp.7-12,

Beamon B.M., (1998) "Supply Chain Design and Analysis: Models and Methods,"International Journal of Production Economics, Vol. 55, No.3, pp.281-294,

Beamon B.M., (1999) "Measuring Supply Chain Performance," International Journal of Operations \& Production Management, Vol. 19 No. 3 pp.7-12,

Bessler S. and Veinott A.F., (1966) Optimal Policy for a Dynamic Multi-Echelon Inventory Model (with S. Bessler). Naval Res. Logistics Quarterly 13 ,4, 355389

Blattberg, R.C., Eppen, G.D., and Lieberman, J. (1981) A Theoretical and Empirical Evaluation of Price Deals for Consumer Non-Durables. Journal of Marketing 45:116-129,

Blumenfeld, D. E., L. D. Burns, J. D. Diltz, C. F. Daganzo. 1985. Analyzing tradeoffs between transportation, inventory and production costs on freight networks. Transportation Res. 19B, pp. 361-380

Bowersox D. J., David J. Closs, (1996) Logistical Management: The Integrated Supply Chain Process, The McGraw-Hill,

Bowersox, D.J. (1969) Readings in Physical Distribution Management: The Logistics of Marketing. Eds. Bowersox, D.J. , La Londe, B.J., and Smykay, E.W., New York: MacMillan, 
Burns, L. D., R. W. Hall, D. E. Blumenfeld, C. F. Daganzo (1985). Distribution strategies that minimize transportation and inventory costs. Oper. Res. 33, pp. 469-490.

Cachon G.P., Zipkin P. H. (1999) Competitive and Cooperative Inventory Policies in a Two-Stage Supply Chain, Management Science, Vol. 45, No.7, pp.936-953

Carter C.R., Jennings M.M., (2002) Social Responsibility and Supply Chain Relationship, Transportation Research. Part E 38: 37-52:

Chan L.M.A. and D. Simchi-Levi (1998) Probabilistic Analyses and Algorithms for Three-Level Distribution Systems, Management Science, Vol. 44, No.11, pp.1562-1576

Chen F, Z. Drezner, J. K. Ryan, and D. Simchi-Levi (2000), Quantifying the Bullwhip Effect in a Simple Supply Chain: The Impact of Forecasting, Lead Times, and Information, Management Sciences, Vol.46, No.3, pp.436-443

Chen F. and Y.S. Zheng (1998), Near-Optimal Echelon-Stock (R,nQ) Policies in Multistage Serial Systems, Operations Research, Vol.46, No.4, pp.592-602

Chen, F. and Y.-S. Zheng, (1997), One-Warehouse Multi-Retailer Systems with Centralized Stock Information. Operations Research 45, 275-287,

Chen, F. and Zheng Y. S. (1994) Lower Bounds for Multi Echelon Stochastic Inventory Systems. Management Science 40, 1426-1443,

Chen, F., (1998) Stationary Policies in Multi-Echelon Inventory Systems with Deterministic Demand and Backlogging. Operations Research, 46 (3), S26-S34,

Clark A.J., Scarf H., (1960) Optimal Policies for a Multi-Echelon Inventory Problem, Management Science, Vol.6, Issue4: 475-490,

Clark, A. and Scarf, H. (1962)."Approximate solutions to a Simple Multi-Echelon Inventory Problem." In Arrow, K., Karlin, S. and Scarf, H. (Ed.) Studies in Applied Probability and Management Science, Stanford University Press, Stanford,

Cohen, M.A. and Lee, H.L. (1988). Strategic Analysis of Integrated ProductionDistribution Systems Models and Methods. Operations Research 36(2), pp.216228

Cooper M C. and L. M. Ellram (1993) Characteristics of Supply Chain Management and the Implications for Purchasing and Logistics Strategy". The International Journal of Logistics Management, Vol.4 No.2 pp. 13-24.

Erkip, N., W. H. Hausman, S. Nahmias, (1990). Optimal centralized ordering policies in multi-echelon inventory systems with correlated demands. Management Science. 36(3) 381-392,

Federgruen A. and Zipkin P. (1984). A combined vehicle routing and inventory allocation problem. Operations Research, 32(5):101 -1036 
Fisher M. (1997), What is the Right Supply Chain for Your Product, Harvard Business Review, March-April, pp. 105-116

Forrester J. W. (1961). Industrial Dynamics, Cambridge, MA: MIT Press.

Fry M. J., R. Kapuscinski, and T. L. Olsen (2001), Coordinating Production and Delivery Under a $(z, Z)$-Type Vendor-Managed Inventory Contract, Manufacturing \& Service Operations Management, Vol. 3, No. 2, pp. 151-173

Geoffrion, A.M. and Graves, G.W. (1974) Multi-Commodity Distribution Design by Benders Decomposition, Management Science 20, pp.822-844,.

Goffman, W. (1980). Scientific Information Systems and the Principle of Selectivity. Praeger Publishers, New York.

Graves S.C. and S.P. Willems (2000) Optimizing Strategic Safety Stock Placement in Supply Chains, Manufacturing \& Service Operations Management, Vol. 2, No. 1 , pp. $68-83$

Graves S.C., (1985) A Multi-Echelon Inventory Model for a Repairable Item with One-forOne Replenishment," Management Science, Vol. 31, pp. 1247-1256,

Gupta, U.G., (1997), Using Citation Analysis To Explore The Intellectual Base, Knowledge Dissemination and Research Impact of Interfaces (1970-1992)”, Interfaces, Vol.27,No.2, pp 85-101

Harper J., (1984). Measuring Business Performance, Gower Publishing Company, Vermont,

Houlihan, J.B. (1985) International Supply Chain Management. Internationa Journal of Physical Distribution \& Materials Management 15:22-38.

Houlihan, J.B. (1988). International Supply Chain Management: A New Approach. Management Decision 26:13-19,

Jones, T.C. and Riley, D.W. (1984).Using Inventory for Competitive Advantage through Supply Chain Management. International Journal of Physical Distribution and Materials Management 15:16-26.

Lee H. L., K. C. So, and C.S. Tang (2000), The Value of Information Sharing in a Two-Level Supply Chain, Management Science, Vol.46, No.5, pp. 626-643

Lee, H.L. and Billington, C. (1993). Material management in decentralized supply chains. Operations Research 41:835-847.

Lee, H.L. and Billington, C. (1995). The evolution of supply-chain-management models and practice at Hewlett-Packard. Interfaces 25:42-63.

Lee, H.L. and K. Moinzadeh, (1987a). Operating Characteristics of a Two-Echelon Inventory System for Repairable and Consumable Items Under Batch Ordering and Shipment Policy, Naval Research Logistics Quarterly 34, 365-380 
Lee, H.L. and K. Moinzadeh, (1987b). Two-Parameter Approximations for MultiEchelon Repairable Inventory Models with Batch Ordering Policy, IIE Transactions 19, 140-149.

Lee, H.L., Padmanabhan, V., and Whang, S. (1997). Information Distortion in a Supply Chain: The Bullwhip Effect. Management Science 43:546-558.

Mendeleyev DI. (1889) The periodic law of chemical elements (Faraday lectures). Journal of the Chemical Society; 55, 643-656. .

Miller T. (2001) Hierarchical Operations and Supply Chain Planning, SpringerVerlag, London.

Pyke D.F. and M. E. Johnson (2002) Sourcing Strategy and Supplier Relationships: Alliances vs. eProcurement, forthcoming in The Practice of Supply Chain Management, Kluwer Publishers, C. Billington, H. Lee, J. Neale, T. Harrison editors.

Reisman, A. (1979) Systems Analysis in Health-Care Delivery, Lexington Books, Lexington, Mass. 311 pages

Reisman, A. (1988). "Finding Researchable Topics Via a Taxonomy of a Field of Knowledge". Operations Research Letters, Vol. 7, No.6, pp. 295-301.

Reisman A. (1989) A System Approach to Identifying Knowledge Voids in Problem Solving Disciplines and Professions: A Focus on the Management Sciences. Knowledge in Society: An International Journal of Knowledge Transfer ; 1(4), 67-86. Spring.

Reisman A. (1992) Management Science Knowledge: It's Creation, Generalization and Consolidation.; Westport CT: Quorum Books Publishing Company.

Reisman, A., (1994) "Creativity in MS/OR: Expanding Knowledge by Consolidating Knowledge", Interfaces, Vol.24, No.3, pp.91-99, May-June

Revelle, C.S. and Laporte, G. (1996). The plant location problem : New models and research prospects. Operations Research 44, pp. 864-874.

Rolstadås A.(1995) Performance Management: A Business Process Benchmarking Approach, Chapman \& Hall, London.

Thomas, D.J. and Griffin, P.M. Coordinated supply chain management. European Journal of Operational Research 94:1-15, 1996.

Vogel DR, Weterbe JC. MIS research: A profile of leading journals and universities. Data Base 1984; Fall: 3-14.

Zinn, W. and Bowersox, D.J. (1988). Planning Physical Distribution with the Principle of Postponement. Journal of Business Logistics 9:117-136, 
Zinn, W. and Levy, M. (1988). Speculative Inventory Management: A Total Channel Perspective. International Journal of Physical Distribution \& Materials Management 18:34-39. 